\title{
Effect of Practice Ownership on Work Environment, Learning Culture, Psychological Safety, and Burnout
}

\author{
Alison Cuellar, $\mathrm{PbD}^{1}$ \\ Alex H. Krist, MD, MPH ${ }^{2}$ \\ Len M. Nichols, $P b D^{1}$ \\ Anton J. Kuzel, MD, MHPE \\ 'Department of Health Administration and \\ Policy, George Mason University, Wash- \\ ington, DC \\ ${ }^{2}$ Department of Family Medicine and Popu- \\ lation Health, Virginia Commonwealth \\ University, \\ Richmond, Virginia
}

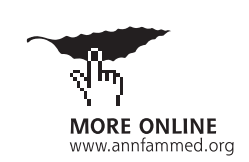

Conflicts of interest: Dr Nichols. received honoraria from the nonprofit Rocky Mountain Health Plans (Grand Junction, Colorado) for organizing content about national trends and facilitating board retreat discussions, and from the American Medical Association for speaking at their annual state advocacy conference on antitrust issues. Dr Nichols is also the Director of George Mason University's Center for Health Policy Research and Etbics, whose 501(c)(3) Foundation account received a grant from America's Health Insurance Plans to support graduate student work on bealth care market issues. Dr Nichols is a member of the unpaid Board of Trustees of the National Committee for Quality Assurance, and an unpaid advisor on payment reform matters to the Patient-Centered Primary Care Collaborative. All other authors declare no conflicts of interest.

\section{CORRESPONDING AUTHOR}

Alison Cuellar, PhD

4400 University Dr, MS 1J3

Fairfax, VA 22030

aevanscu@gmu.edu

\begin{abstract}
PURPOSE Physicians have joined larger groups and hospital systems in the face of multiple environmental challenges. We examine whether there are differences across practice ownership in self-reported work environment, a practice culture of learning, psychological safety, and burnout.
\end{abstract}

METHODS Using cross-sectional data from staff surveys of small and medium-size practices that participated in EvidenceNOW in Virginia, we tested for differences in work environment, culture of learning, psychological safety, and burnout by practice type. We conducted weighted multivariate linear regression of outcomes on ownership, controlling for practice size, specialty mix, payer mix, and whether the practice was located in a medically underserved area. We further analyzed clinician and staff responses separately.

RESULTS Participating were 104 hospital-owned and 61 independent practices and 24 federally qualified health centers (FQHCs). We analyzed 2,005 responses from practice clinicians and staff, a response rate of $49 \%$. Working in a hospitalowned practice was associated with favorable ratings of work environment, psychological safety, and burnout compared with independent practices. When we examined separately the responses of clinicians vs staff, however, the association appears to be largely driven by staff.

CONCLUSIONS Hospital ownership was associated with positive perceptions of practice work environment and lower burnout for staff relative to independent ownership, whereas clinicians in FQHCs perceive a more negative, less joyful work environment and burnout. Our findings are suggestive that clinician and nonclinician staff perceive practice adaptive reserve differently, which may have implications for creating the energy for ongoing quality improvement work.

Ann Fam Med 2018;16(Suppl 1):S44-S51. https://doi.org/10.1370/afm.2198.

\section{INTRODUCTION}

T he Heart of Virginia Healthcare collaborative is 1 of 7 regional efforts supported by the Agency for Healthcare Research and Quality (AHRQ). ${ }^{1}$ In 2015, AHRQ launched EvidenceNOW:

Advancing Heart Health in Primary Care, a multiyear pragmatic trial. EvidenceNOW is designed to generate information about the effectiveness of external quality improvement support in helping small and medium-size primary care practices use patient-centered outcomes research findings to improve the heart health of their patients. The project also is designed to determine what works best in developing organizational capacity for ongoing practice improvement in primary care.

Our EvidenceNOW intervention is based on the theory that, faced with a complex environment, practices must attain the adaptive reserve needed for higher order practice transformation. ${ }^{2}$ Our approach is predicted on the assumption that attention to overall practice vitality and function-across clinicians and nonclinician staff-is essential to quality improvement activities, including attention to cardiovascular risk factors. ${ }^{3}$ Adaptive reserve contains many elements, including a positive or joyful work environment and a culture of learning. These elements, along with 
psychological safety, reflecting a shared belief that a team is safe for interpersonal risk taking, are hypothesized to underlie successful change. ${ }^{4}$

But how large should the optimal team be? Independent physicians are joining hospital systems or larger groups at a rapid pace, partly to achieve better bargaining power in the face of dominant health plans, and partly to exploit natural economies of scale in information technology, quality improvement, and reporting systems, especially as performance incentives have increased among public and private payers. ${ }^{5}$ In addition, physicians leave independent practice in response to burnout from a lack of career fit ${ }^{6}$ or dissatisfaction with staffing models that require performing major nonphysician, non-revenue-generating work. ${ }^{78}$ Finally, the Karasek model postulates that psychological strain results from the joint effects of conflicting demands of a work situation and the decision-making discretion available to the individual facing those demands. ${ }^{9}$

Across all physician types, the share of physicians who own their own practices was $51 \%$ in 2014 , down from $76 \%$ in $1983 .{ }^{10}$ Many of these practices are now hospital owned or affiliated. By 2014 the proportion of physicians who worked in hospital-owned or hospital-affiliated practices had reached one-third. As a by-product, primary care physicians are working in larger groups. In 2015, more than two-thirds of primary care physicians were in groups of 11 clinicians or more. ${ }^{11}$ Given that our participating practices represented independent and hospital system practices, as well as federally qualified health centers (FQHCs), we hypothesized that practices would differ by their ownership structure in the degree of clinician and nonclinician burnout, work environment, and psychological safety at baseline.

As clinicians shift to larger practices, so do their nonclinician staff. Previous studies have found that burnout varies substantially by occupation and has been found to be higher for clinicians than staff. ${ }^{12}$ At the same time, nonclinician staff may perceive reduced financial risk and therefore greater job security when practices are under hospital ownership. Existing studies provide little insight on ownership differences on adaptive reserve and burnout, whether for clinicians or staff.

Given the current trend for primary care clinicians to become employees rather than independent practice owners ${ }_{1}^{13}$ we sought to test for cross-sectional, baseline differences across independent and hospitalowned practices on organizational capabilities and burnout. Previous literature on practice ownership has addressed differences in overall cost of care, ${ }_{1}^{14-16}$ rates of preventable hospital admissions, ${ }_{1}^{17}$ hospital choice ${ }_{1}^{18}$ structures needed for quality improvement work, ${ }^{19,20}$ and quality measures. ${ }^{21,22}$ Our study extends this literature, comparing independent and hospital system practices on both personal and environmental psychological factors that can potentially support quality improvement efforts. We also report on these outcomes for FQHCs, which function as vital access points for underserved populations. We hypothesized that clinicians in FQHCs would report a positive organizational environment, reflecting a shared commitment to underserved populations, but also higher burnout given their challenging financial environment and high patient demands.

\section{METHODS}

The Heart of Virginia Healthcare study recruited small and medium-size primary care practices to participate in an intervention to "restore joy in practice" as a means of improving quality. This article reports on crosssectional analyses of baseline survey data collected in 2016 and 2017 related to practice characteristics, selfreported burnout, a positive work environment, psychological safety, and a practice culture of learning.

\section{Recruitment}

Practices were initially recruited through connections with Virginia's allopathic medical schools, the Virginia Quality Improvement Organization (Health Quality Innovators), and the Health Information Technology Extension Program in Virginia. Additionally, practices were approached at the Virginia Academy of Family Physicians and the Virginia chapter of the American College of Physicians annual meetings. To incentivize participating practices, we offered payments of $\$ 500$ per practice to complete survey questionnaires. Our study was approved by the Virginia Commonwealth University and George Mason University institutional review boards.

\section{Data and Study}

Our primary outcomes included measures of a positive work environment, a culture of learning, psychological safety, and burnout. These were obtained from baseline surveys of clinicians and staff. All survey questionnaires were administered online with paper follow-up. Our primary outcomes were items from the adaptive reserve instrument, specifically items which represent a culture of learning, psychological safety, and a positive work environment, ${ }^{23,24}$ as well as a measure of burnout.

A positive work environment was captured with 2 adaptive reserve items, "most people in the practice seem to enjoy their work" and "this practice is a place of joy and hope." A learning culture was captured with "it is hard to get things to change in our practice," whereas psychological safety was captured with 
responses to "members of this practice are able to bring up problems and tough issues." Each of these items was ranked by respondents on a 5 -point scale from strongly disagree to strongly agree. Adaptive reserve responses were recoded as appropriate so that higher values reflected more positive outcomes.

Individuals also were asked about their degree of burnout using a nonproprietary single-item burnout indicator that instructs respondents to define burnout for themselves. The 5 possible response categories were as follows ${ }^{25}$ : (1) "I enjoy my work. I have no symptoms of burnout." (2) "Occasionally I am under stress, and I don't always have as much energy as I once did, but I don't feel burned out." (3) "I am definitely burning out and have one or more symptoms of burnout, such as physical and emotional exhaustion."

(4) "The symptoms of burnout that I am experiencing would not go away. I think about frustration at work a lot." (5) "I feel completely burned out and often wonder if I can go on. I am at the point where I may need some changes or may need to seek some sort of help." This item was used in the Physician Worklife Study ${ }^{26}$ and in the Healthy Workplace Trial ${ }^{27}$ and has been found to perform well against a propriety single-item version of the Maslach Burnout Inventory emotional exhaustion measure. ${ }^{28}$ In our statistical models, we tested the respondents' impact on the full burnout scale and also on an indicator of burnout as defined by a rating of 3 or higher.

A second questionnaire was completed by a lead clinician or practice manager and contained measures of practice characteristics, including ownership, practice size, single or multispecialty practice, whether the practice was recognized as a primary care medical home, whether the practice was located in a medically underserved area, and payer mix. Responses on total practice size were used to calculate response rates on the individual-level surveys. Practices were categorized as independent vs owned by a hospital system or as a FQHC. Independent practices included members of independent practice associations that were not owned by a hospital system. Ownership responses were confirmed by telephone, and status as a FQHC and whether the practice was located in a designated medical underserved area were confirmed against public reports maintained by the Health Resources and Services Administration. Practice size was organized into 3 categories: 1 to 5 clinicians, 6 to 10 clinicians, and 11 or more clinicians.

\section{Statistical Approach}

We conducted ordered probit regression models because our outcomes were ordered categories. Individual survey-based outcomes were weighted by the inverse of the response rate within practice, and standard errors were adjusted for clustering at the practice level. We first analyzed all responses, and then we separately analyzed clinician and staff responses. We controlled for the following covariates: practice size, whether single or multispecialty mix, whether the practice was accredited as a primary care medical home, whether the practice was located in a designated medically underserved area, the percentage of patients with Medicare coverage, and the percentage of patients with Medicaid coverage or who were not insured.

\section{RESULTS \\ Study Population}

We secured the participation of 67 independent practices, 116 hospital system practices, and 24 FQHCs, which represents roughly $20 \%$ of eligible small and medium-size primary care practices in Virginia.

Our response rate for the individual survey was $48 \%$ and $93 \%$ for the practice characteristics survey. Of 2,109 returned questionnaires, 2,005 with complete responses on all relevant items were used in the analysis. The 2,005 responses were obtained from 190 practices, including 700 questionnaires from 61 independent practices, 931 from 104 hospital system practices, and 374 from 24 FQHCs. Twenty-four percent of survey respondents were clinicians after adjusting for weighting $(n=471)$. The baseline characteristics of the individual survey responses overall, and by whether they are independent, hospital owned, or FQHC, are displayed in Table 1 .

\section{Culture of Learning}

Survey respondents rated their practices similarly on culture of learning, ie, how difficult it is to get things done, across independent, hospital system, and FQHC practices (Table 1). On a scale of 0 to 5 , the overall average was 3.0, or neutral. Unadjusted differences across practice types were not statistically significant, and in multivariate models controlling for practice size, practice type, accreditation for primary care medical home, and payer mix, the differences across independent vs hospital owned and independent vs FQHC were also not statistically significant (Table 2 and the Supplemental Table, http://www.annfammed. org/content/16/Suppl_1/S44/supp1/DC1).

\section{Work Environment}

On average, staff reported a relatively positive work environment at a mean rating of $3.6(95 \% \mathrm{CI}, 3.5-3.6)$ for "enjoyment with work" and of 3.5 (95\% CI, 3.43.6) for practice is a "place of joy and hope" as shown in Table 1. Given the 5 response categories, the mean 
Table 1. Survey Respondent and Practice Sample Characteristics

\begin{tabular}{|c|c|c|c|c|}
\hline Characteristic & All Practices $^{a}$ & Independent & $\begin{array}{l}\text { Hospital } \\
\text { Owned }\end{array}$ & $\begin{array}{c}\text { Federally } \\
\text { Qualified } \\
\text { Health Center }\end{array}$ \\
\hline Total responding & 1,973 & 690 & 910 & 373 \\
\hline Clinicians responding & 467 & 170 & 239 & 58 \\
\hline Staff responding & 1,506 & 520 & 671 & 315 \\
\hline \multicolumn{5}{|l|}{ Outcome } \\
\hline Culture of learning, mean score $(95 \% \mathrm{Cl})^{\mathrm{b}}$ & $3.0(2.9-3.0)$ & $2.9(2.8-3.1)$ & $3.0(2.9-3.1)$ & $2.9(.2 .7-3.0)$ \\
\hline \multicolumn{5}{|l|}{ Work environment, mean score $(95 \% \mathrm{Cl})^{\mathrm{b}}$} \\
\hline Enjoyment with work & $3.6(3.5-3.7)$ & $3.5(3.3-3.6)$ & $3.7(3.6-3.9)^{c}$ & $3.4(3.3-3.6)$ \\
\hline Place of joy and hope & $3.5(3.4-3.6)$ & $3.4(3.2-3.6)$ & $3.6(3.5-3.7)^{c}$ & $3.4(3.2-3.6)$ \\
\hline Psychological safety, mean score $(95 \% \mathrm{Cl})^{\mathrm{b}}$ & $3.5(3.4-3.6)$ & $3.4(3.2-3.5)$ & $3.7(3.6-3.9)^{\mathrm{d}}$ & $3.2(3.0-3.3)$ \\
\hline Burnout scale, mean score $(95 \% \mathrm{Cl})^{\mathrm{b}}$ & $2.1(2.00-2.14)$ & $2.2(2.1-2.3)$ & $2.0(1.9-2.1)^{d}$ & $2.1(2.0-2.2)$ \\
\hline Burnout indicator, mean score $(95 \% \mathrm{Cl})^{e}$ & $0.24(0.21-0.28)$ & $0.28(0.24-0.34)$ & $0.20(0.15-0.26)$ & $0.27(0.22-0.33)$ \\
\hline \multicolumn{5}{|l|}{ Practice } \\
\hline \multicolumn{5}{|l|}{ No. of clinicians, mean \% $\left(95 \%\right.$ Cl) ${ }^{a}$} \\
\hline $1-5$ & $38.9(30.9-47.5)$ & $27.5(17.4-40.6)$ & $49.4(36.3-62.6)$ & $34.7(17.9-56.9)$ \\
\hline $6-10$ & $32.1(24.0-41.5)$ & $30.6(18.4-46.2)$ & $30.4(19.8-43.6)$ & $40.3(19.2-65.7)$ \\
\hline$\geq 11$ & $29.0(19.2-41.1)$ & $41.9(25.7,-60.0)$ & $20.2(8.5-40.9)$ & $24.9(7.7-56.7)$ \\
\hline \multicolumn{5}{|l|}{ Specialty mix, mean \% $(95 \% \mathrm{Cl})$} \\
\hline Single specialty & $60.7(50.4-70.2)$ & $76.6(58.8-88.3)$ & $62.4(47.1-75.5)$ & $21.5(8.8-43.9)^{f}$ \\
\hline Multispecialty & $39.3(29.8-40.6)$ & $23.4(11.7-41.2)$ & $37.6(24.5-52.9)$ & $78.4(56.1-91.2)$ \\
\hline Medically underserved area, mean \% (95\% Cl) & $69.3(59.7-77.4)$ & $51.9(35.6-67.9)$ & $78.0(67.7-85.7)^{d}$ & $83.0(53.6-95.3)$ \\
\hline Patients with Medicare, mean \% (95\% Cl) & $28.1(24.2-32.0)$ & $29.1(21.6-36.6)$ & $30.9(25.5-36.3)$ & $18.9(13.4-24.4)^{c}$ \\
\hline $\begin{array}{l}\text { Patients with Medicaid/uninsured, mean \% } \\
(95 \% \mathrm{Cl})\end{array}$ & $24.1(19.1-29.1)$ & $14.9(10.0-19.8)$ & $19.6(14.6-24.7)$ & $56.8(45.5-68.0)^{\dagger}$ \\
\hline Total practices, No. & 189 & 61 & 104 & 24 \\
\hline \multicolumn{5}{|c|}{$\begin{array}{l}\text { Note: } P \text { values generated by comparison with independent practices using } t \text { tests for differences in means, and } \chi^{2} \text { tests of independence for proportions, adjusted fo } \\
\text { the survey design. }\end{array}$} \\
\hline \multicolumn{5}{|c|}{ a Estimates adjusted for practice-level nonresponse. } \\
\hline \multicolumn{5}{|c|}{$\begin{array}{l}\text { b Scored on a scale from } 1 \text { to } 5 \text {, where higher scores indicate higher levels; see text for response categories. } \\
\text { c } P<.05 \text {. } \\
\text { d } P<.01\end{array}$} \\
\hline
\end{tabular}

responses fall between neutral and agree. Adjusting for covariates, being a hospital-owned practice was associated with a higher rating on enjoyment with work ( $\beta=0.273 ; 95 \% \mathrm{CI}, 0.014-0.533)$ relative to independent practices (Table 2). Table 2 also shows the estimated incremental difference of hospital ownership relative to independent practices at each response category. Thus, hospital ownership is associated with being $6 \%$ more likely to report strongly agree with enjoyment with work and $1.7 \%$ less likely to report strongly disagree. Differences in ratings of the practice as a place of joy and hope between hospitalowned and independent practices, however, were not statistically significant. Further, there were no statistically significant differences in the work environment ratings between independent practices and FQHCs; therefore, estimated incremental differences by response category between FQHCs and independent practices are not displayed in the table.

\section{Psychological Safety}

Self-reported psychological safety was rated at 3.5 on average in the total sample, between neutral and agree. Higher ratings were reported in hospital-owned practices than in independent practices, adjusting for covariates ( $\beta=0.363 ; 95 \% \mathrm{CI}, 0.118-0.609)$, and hospital ownership is associated with being $8.5 \%$ more likely to report strongly agree with the question on psychological safety and $2.7 \%$ less likely to report strongly disagree. In contrast, FQHCs experienced lower psychological safety than independent practices, but differences were not statistically significant, adjusting for covariates.

\section{Burnout}

Measured on a 1 to 5 scale, burnout was rated at 2.1 on average, which roughly corresponds to occasionally being under stress. Adjusting for covariates, being in a hospital-owned practice was associated with reporting 
Table 2. Association of Practice Ownership With Work Environment, Learning Culture, Psychological Safety, and Burnout, All Survey Respondents

\begin{tabular}{|c|c|c|c|c|c|}
\hline Characteristic & $\begin{array}{c}\text { Culture } \\
\text { of Learning }^{a} \\
\beta(95 \% \mathrm{Cl})\end{array}$ & $\begin{array}{c}\text { Enjoyment } \\
\text { With Work }^{\mathrm{a}} \\
\beta(95 \% \mathrm{Cl})\end{array}$ & $\begin{array}{c}\text { Place of Joy } \\
\text { and Hope } \\
\beta(95 \% \mathrm{Cl})\end{array}$ & $\begin{array}{c}\text { Psychological } \\
\text { Safety } \\
\beta(95 \% \mathrm{Cl}) \\
\end{array}$ & $\begin{array}{l}\text { Burnout }{ }^{a} \\
\beta(95 \% \mathrm{Cl})\end{array}$ \\
\hline \multicolumn{6}{|c|}{ Practice ownership } \\
\hline Independent & Reference & Reference & Reference & Reference & Reference \\
\hline Hospital & $\begin{array}{c}0.062 \\
(-0.141 \text { to } 0.265)\end{array}$ & $\begin{array}{c}0.273 \\
(0.014 \text { to } 0.533)^{b}\end{array}$ & $\begin{array}{c}0.194 \\
(-0.057 \text { to } 0.446)\end{array}$ & $\begin{array}{c}0.363 \\
(0.118 \text { to } 0.609)^{c}\end{array}$ & $\begin{array}{c}-0.287 \\
(-0.509 \text { to }-0.063)^{t}\end{array}$ \\
\hline $\mathrm{FQHC}$ & $\begin{array}{c}-0.106 \\
(-0.385 \text { to } 0.172)\end{array}$ & $\begin{array}{c}-0.171 \\
(-0.505 \text { to } 0.162)\end{array}$ & $\begin{array}{c}-0.191 \\
(-0.536 \text { to } 0.155)\end{array}$ & $\begin{array}{c}-0.264 \\
(-0.549 \text { to } 0.021)\end{array}$ & $\begin{array}{c}-0.048 \\
(-0.364 \text { to } 0.268)\end{array}$ \\
\hline
\end{tabular}

Incremental difference between hospital-owned and independent practices by response category

\begin{tabular}{lccrrr}
\hline Response category & Difference & Difference & Difference & Difference & Difference \\
\hline Level 1 & -0.011 & -0.017 & -0.011 & -0.027 \\
Level 2 & -0.012 & -0.041 & -0.028 & -0.054 \\
Level 3 & -0.001 & -0.042 & -0.037 & -0.055 & -0.010 \\
Level 4 & 0.014 & 0.039 & 0.033 & 0.052 \\
Level 5 & 0.009 & 0.061 & 0.043 & 0.085 \\
Total number & 1,989 & 1,988 & 1,988 & -0.023 & 1,992 \\
\hline
\end{tabular}

$\mathrm{FQHC}=$ federally qualified health center

Note: Multivariate ordered probit models adjusted for practice-level nonresponse and clustering at practice level and controlling for ownership (independent, hospital system, or federally qualified health center), whether practice is located in a medical underserved area, practice size, single- or multispecialty practice, percentage of patients with Medicare coverage, and percentage of patients with Medicaid coverage or uninsured.

a Scored on a scale from 1 to 5 , where higher scores indicate higher levels; see text for response categories.

b $P<.05$.

c $P<.01$.

lower burnout values relative to independent practices $(\beta=-0.287 ; 95 \% \mathrm{CI},-0.509$ to 0.063$)$. Hospital ownership was associated with being $9.8 \%$ more likely to report "I enjoy my work. I have no symptoms of burnout" and 2\% less likely to report "I feel completely burned out and often wonder if I can go on." Differences between FQHCs and independent practices were not statistically different.

Separately, we ran logistic models where burnout was defined at a threshold of 3 or higher. Overall, $24 \%$ of respondents reported burnout at this threshold or higher, with rates lowest for hospital-owned practices (20\%) and highest for independent practices (28\%). Adjusting for other covariates, the odds of being at or above the burnout threshold were not statistically different across practice ownership type (results not shown).

\section{Clinicians vs Staff Respondents}

We then examined responses from clinicians and staff separately (Table 3a). Clinicians include physicians, nurse practitioners, and physician assistants. Among clinicians there was no statistically significant difference across independent and hospital-owned practices in ratings across culture of learning, work environment indicators, psychological safety, or burnout. Clinicians in FQHCs, however, on average reported lower ratings of culture of learning $(\beta=0.470 ; 95 \%$ $\mathrm{CI},-0.919$ to -0.021$)$, lower ratings of the work environment as measured by enjoyment with work $(\beta=-0.552 ; 95 \% \mathrm{CI},-0.996$ to -0.109$)$, and the practice as a place of joy $(\beta=-0.567 ; 95 \% \mathrm{CI},-1.089$ to $-0.405)$. FQHC clinicians also reported lower psychological safety $(\beta=-0.723 ; 95 \% \mathrm{CI},-1.194$ to -0 . 252). Incremental differences by response category are reflected in Table 3a for FQHC vs independent practices. Differences in ratings of burnout between clinicians in FQHCs and independent practices were not statistically significant, however. We ran separate models for physicians only and found qualitatively similar results (results not shown).

Among staff (Table $3 \mathrm{~b}$ ), there were no differences between FQHCs and independent practices on any of the outcomes. Staff employed by hospital system practices, however, reported greater psychological safety than staff in independent practices $(\beta=0.372 ; 95 \% \mathrm{CI}$, $0.131-0.613)$ and lower burnout $(\beta=-0.328 ; 95 \% \mathrm{CI}$, -0.608 to -0.049$)$, adjusting for covariates. The corresponding incremental differences between hospitalowned and independent practices are shown in Table $3 \mathrm{~b}$. Differences in ratings of enjoyment with work and the practices as a place of joy and hope were not statistically significant. 
Table 3a. Association of Practice Ownership With Work Environment, Learning Culture, Psychological Safety, and Burnout, Clinician Respondents

\begin{tabular}{|c|c|c|c|c|c|}
\hline Characteristic & $\begin{array}{c}\text { Culture } \\
\text { of Learning } \\
\beta(95 \% \mathrm{Cl})\end{array}$ & $\begin{array}{c}\text { Enjoyment } \\
\text { With Work } \\
\beta(95 \% \mathrm{Cl})\end{array}$ & $\begin{array}{l}\text { Place of Joy } \\
\text { and } \mathrm{Hope}^{\mathrm{a}} \\
\beta(95 \% \mathrm{Cl})\end{array}$ & $\begin{array}{c}\text { Psychological } \\
\text { Safety } \\
\beta(95 \% \mathrm{Cl})\end{array}$ & $\begin{array}{l}\text { Burnout }^{\mathrm{a}} \\
\beta(95 \% \mathrm{Cl})\end{array}$ \\
\hline \multicolumn{6}{|c|}{ Practice ownership } \\
\hline Independent & Reference & Reference & Reference & Reference & Reference \\
\hline Hospital & $\begin{array}{c}-0.131 \\
(-0.409 \text { to } 0.146)\end{array}$ & $\begin{array}{c}0.094 \\
(-0.243 \text { to } 0.430)\end{array}$ & $\begin{array}{c}-0.063 \\
(-0.403 \text { to } 0.276)\end{array}$ & $\begin{array}{c}0.100 \\
(-0.242 \text { to } 0.443)\end{array}$ & $\begin{array}{c}-0.192 \\
(-0.545 \text { to } 0.161)\end{array}$ \\
\hline $\mathrm{FQHC}$ & $\begin{array}{c}-0.470 \\
(-0.919 \text { to }-0.021)^{b}\end{array}$ & $\begin{array}{c}-0.552 \\
(-0.996 \text { to }-0.109)^{b}\end{array}$ & $\begin{array}{c}-0.567 \\
(-1.089 \text { to }-0.045)^{b}\end{array}$ & $\begin{array}{c}-0.723 \\
(-1.194 \text { to }-0.252)^{c}\end{array}$ & $\begin{array}{c}0.219 \\
(-0.317 \text { to } 0.755)\end{array}$ \\
\hline
\end{tabular}

Incremental difference between FQHC and independent practices by response category

\begin{tabular}{lccccc}
\hline Response category & Difference & Difference & Difference & Difference & Difference \\
\hline Level 1 & 0.108 & 0.033 & 0.045 & 0.088 & -0.055 \\
Level 2 & 0.071 & 0.088 & 0.081 & 0.122 & -0.021 \\
Level 3 & -0.009 & 0.083 & 0.089 & 0.060 & 0.033 \\
Level 4 & -0.109 & -0.117 & -0.129 & -0.153 & 0.019 \\
Level 5 & -0.061 & -0.088 & -0.086 & -0.116 & 0.024 \\
No. of respondents & 467 & 466 & 466 & 467 & 466 \\
\hline
\end{tabular}

$\mathrm{FQHC}=$ federally qualified health center.

Note: Multivariate ordered probit models adjusted for practice-level nonresponse and clustering at the practice level and controlling for ownership (independent, hospital system, or federally qualified health center), whether practice is located in a medical underserved area, practice size, single or multi-specialty practice, percentage of patients with Medicare coverage, and percentage of patients with Medicaid coverage or uninsured.

a Scored on a scale from 1 to 5 , in which higher scores indicate higher levels; see text for response categories.

$P<.05$.

c $P<.01$

Table 3b. Association of Practice Ownership With Work Environment, Learning Culture, Psychological Safety and Burnout, Staff Respondents

\begin{tabular}{|c|c|c|c|c|c|}
\hline Characteristic & $\begin{array}{c}\text { Culture } \\
\text { of Learning } \\
\beta(95 \% \mathrm{Cl})\end{array}$ & $\begin{array}{l}\text { Enjoyment } \\
\text { With Work }^{a} \\
\beta(95 \% \mathrm{Cl})\end{array}$ & $\begin{array}{l}\text { Place of Joy } \\
\text { and Hope } \\
\beta(95 \% \mathrm{Cl})\end{array}$ & $\begin{array}{c}\text { Psychological } \\
\text { Safety }^{\mathrm{a}} \\
\beta(95 \% \mathrm{Cl})\end{array}$ & $\begin{array}{l}\text { Burnout }^{a} \\
\beta(95 \% \mathrm{Cl})\end{array}$ \\
\hline \multicolumn{6}{|l|}{ Ownership } \\
\hline Independent & Reference & Reference & Reference & Reference & Reference \\
\hline Hospital-owned & $\begin{array}{c}0.111 \\
(-0.157 \text { to } 0.378)\end{array}$ & $\begin{array}{c}0.282 \\
(-0.007 \text { to } 0.571)\end{array}$ & $\begin{array}{c}0.275 \\
(-0.012 \text { to } 0.562)\end{array}$ & $\begin{array}{c}0.372 \\
(0.131 \text { to } 0.613)^{b}\end{array}$ & $\begin{array}{c}-0.328 \\
(-0.608 \text { to }-0.049)^{c}\end{array}$ \\
\hline $\mathrm{FQHC}$ & $\begin{array}{c}-0.018 \\
(-0.367 \text { to } 0.331)\end{array}$ & $\begin{array}{c}-0.063 \\
(-0.446 \text { to } 0.321)\end{array}$ & $\begin{array}{c}-0.085 \\
(-0.443 \text { to } 0.274)\end{array}$ & $\begin{array}{c}-0.157 \\
(-0.456 \text { to } 0.141)\end{array}$ & $\begin{array}{c}-0.066 \\
(-0.411 \text { to } 0.280)\end{array}$ \\
\hline
\end{tabular}

Incremental difference between hospital-owned and independent practices by response category

\begin{tabular}{|c|c|c|c|c|c|}
\hline Response category ${ }^{a}$ & Difference & Difference & Difference & Difference & Difference \\
\hline Level 1 & -0.020 & -0.020 & -0.017 & -0.030 & 0.116 \\
\hline Level 2 & -0.044 & -0.044 & -0.040 & -0.056 & -0.018 \\
\hline Level 3 & -0.041 & -0.041 & -0.049 & -0.057 & -0.051 \\
\hline Level 4 & 0.044 & 0.044 & 0.045 & 0.060 & -0.026 \\
\hline Level 5 & 0.061 & 0.061 & 0.062 & 0.082 & -0.021 \\
\hline
\end{tabular}

$\mathrm{FQHC}=$ federally qualified health center.

Note: Multivariate ordered probit models adjusted for practice-level nonresponse and clustering at the practice level and controlling for ownership (independent, hospital system, or federally qualified health center), whether practice is located in a medical underserved area, practice size, single or multi-specialty practice, percentage of patients with Medicare coverage, and percentage of patients with Medicaid coverage or uninsured.

a Scored on a scale from 1 to 5 , in which higher scores indicate higher levels; see text for response categories.

b $P<.01$.

c $P<.05$. 


\section{DISCUSSION}

We found more favorable ratings of work environment psychological safety, and burnout in hospital-owned practices compared with independent practices, controlling for a variety of practice characteristics. These differences were largely driven by staff rather than clinician respondents. Although our results broaden our understanding of practice ownership with respect to a variety of outcomes, our results do not explain why nonclinical staff at hospital-owned practices appear to be in a better place psychologically compared with their clinician colleagues.

We also found that clinicians in FQHCs were less likely to report a positive work environment than clinicians in independent practices, although clinicians in FQHCs did not report greater burnout. That clinicians in FQHCs generally see their practices as more of a learning environment is not surprising. The relatively strong culture of learning in FQHCs may reflect a history of learning support from the US Healthcare Resources and Services Administration and the state primary care association (the Virginia Community Healthcare Association). Our hypothesis of higher scores among FQHC clinicians on other indicators of a positive work environment was not supported, possibly related to the FQHC's patient population, staffing, resources, reimbursement, or other factors. We are in the process of conducting a qualitative assessment of practices to better understand these differences.

Our study has several limitations, including that results may not generalize to other practices within or outside Virginia. Because the literature provides little guidance on the clinical importance of the differences we measured for select adaptive reserve items, results should be interpreted with caution. In addition, each dimension of change was measured with a limited number of questions. Given the size of our sample, we were not able examine physicians separately from other clinician types. Our survey also was not designed to identify the mechanisms that drive the differences in outcomes across staff roles. The association between ownership and outcomes may be causally driven by the ownership structure, but it also may be driven by sorting of clinicians into practices by type. Further research should explore the potential reasons for ownership differences in outcomes and the clinical significance of differences in responses to adaptive reserve questions.

To our knowledge, this study is the first that compares independent practices, hospital system practices, and FQHCs on elements from the adaptive reserve survey that address culture of learning, enjoyable work environment, psychological safety, and burnout-elements that we see as essential aspects of joy in prac- tice. ${ }^{29}$ Our findings suggest that staff may be critical to building overall practice adaptive reserve and thus creating the energy for ongoing quality improvement work. Staff also provide a novel validation of the importance of team-based care models in primary care

To read or post commentaries in response to this article, see it online at http://www.AnnFamMed.org/content/16/Suppl_1/S44.

Key words: practice ownership; burnout; adaptive reserve

Submitted June 15, 2017; submitted, revised, December 15, 2017; accepted December 22, 2017.

Funding support: Publication of this article was supported by the Agency for Healthcare Research and Quality (AHRQ) through contract No. HHSA290201200019l, and grant No. R18 HS023913.

Disclaimer: This work represents the opinions of the authors and should not be interpreted as official positions of the Agency for Healthcare Research and Quality or the US Department of Health and Human Services.

Supplementary materials: Available at http://www.AnnFamMed. org/content/16/Suppl_/S44/suppl/DC1/.

\section{References}

1. US Department of Health and Human Services. Agency for Healthcare Research and Quality (AHRQ). Evidence Now: advancing heart health in primary care. https://www.ahrq.gov/evidencenow/index. html. Accessed Jun 10, 2017.

2. Nutting PM, Crabtree BF, Miller WF, et al. Journey to the patientcentered medical home: a qualitative analysis of the experience of practices in the National Demonstration Project. Ann Fam Med. 2010;8(Suppl 1):545-556. http://www.annfammed.org/content/8/ Suppl_1/s45.full.pdf+html.

3. Nutting PA, Crabtree BF, Miller WL, Stange $K C$, Stewart $E$, Jaén C. Transforming physician practices to patient-centered medical homes: lessons from the national demonstration project. Health Aff (Millwood). 2011;30(3):439-445.

4. Edmondson A. psychological safety and learning behavior in work teams. Adm Sci Q. 1999;44(2):350-383

5. Casalino LP. The Medicare Access and CHIP Reauthorization Act and the corporate transformation of American medicine. Health Aff (Millwood). 2017;36(5):865-869.

6. Shanafelt TD, West CP, Sloan JA, et al. Career fit and burnout among academic faculty. Arch Intern Med. 2009;169(10):990-995.

7. Sinsky C, Colligan L, Li L, et al. Allocation of physician time in ambulatory practice: a time and motion study in 4 specialties. Ann Intern Med. 2016;165(11):753-760.

8. Kuzel AJ. Ten steps to a patient-centered medical home. Fam Pract Manag. 2009;16(6):18-24

9. Karasek RA. Job demands, job decision latitude, and mental strain: implications for job redesign. Adm Sci Q. 1979;24(2):285-308.

10. Kane CK. Updated data on physician practice arrangements: inching toward hospital ownership. Chicago, IL: American Medical Association: 2015 https://www.m3globalresearch.com/img/resources/ AMA_PRP_Physician_Practice_Arrangements.pdf

11. Muhlestein DB, Smith NJ. Physician Consolidation: Rapid Movement From Small To Large Group Practices, 2013-15. Health Aff (Millwood). 2016;35(9):1638-1642. 10.1377/hlthaff.2016.0130. 
12. Dolan ED, Mohr D, Lempa M, et al. Using a single item to measure burnout in primary care staff: a psychometric evaluation. J Gen Intern Med. 2015;30(5):582-587.

13. Isaacs SL, Jellinek PS, Ray WL. The independent physician-going, going.... N Engl J Med. 2009;360(7):655-657.

14. Robinson JC, Miller K. Total expenditures per patient in hospitalowned and physician-owned physician organizations in California. JAMA. 2014;312(16):1663-1669.

15. McWilliams JM, Chernew ME, Zaslavsky AM, Hamed P, Landon $B E$. Delivery system integration and health care spending and quality for Medicare beneficiaries. JAMA Intern Med. 2013;173(15): 1447-1456.

16. MCWilliams JM. Changes in Medicare shared savings program savings from 2013 to 2014. JAMA. 2016;316(16):1711-1713.

17. Casalino LP, Pesko MF, Ryan AM, et al. Small primary care physician practices have low rates of preventable hospital admissions. Health Aff (Millwood). 2014;33(9):1680-1688.

18. Baker LC, Bundorf MK, Kessler DP. The effect of hospital/physician integration on hospital choice. J Health Econ. 2016;50:1-8. 10.1016/j. jhealeco.2016.08.006.

19. Solberg LI, Asche SE, Shortell SM, et al. Is integration in large medical groups associated with quality? Am J Manag Care. 2009; 15(6):e34-e41.

20. Bishop TF, Shortell SM, Ramsay PP, Copeland KR, Casalino LP. Trends in hospital ownership of physician practices and the effect on processes to improve quality. Am J Manag Care. 2016;22(3): 172-176.

21. Mehrotra A, Epstein AM, Rosenthal MB. Do integrated medical groups provide higher-quality medical care than individual practice associations? Ann Intern Med. 2006;145(11):826-833.
22. Crespin DJ, Christianson JB, McCullough JS, Finch MD. Health system consolidation and diabetes care performance at ambulatory Clinics. Health Serv Res. 2016;51(5):1772-1795.

23. Nutting PA, Crabtree BF, Stewart EE, et al. Effect of facilitation on practice outcomes in the National Demonstration Project model of the patient-centered medical home. Ann Fam Med. 2010;8(Suppl 1):S33-\$44, S92.

24. Miller WL, Crabtree BF, Nutting PA, Stange KC, Jaén CR. Primary care practice development: a relationship-centered approach. Ann Fam Med. 2010;8(Suppl 1):S68-S79, S92.

25. Primack BA, Dilmore TC, Switzer GE, et al. Burnout among early career clinical investigators. Clin Trans/ Sci. 2010;3(4):186-188.

26. Rohland BM, Kruse GR, Rohrer JE. Validation of a single-item measure of burnout against the Maslach Burnout Inventory among physicians. Stress Health. 2004;20(2):75-79.

27. Linzer M, Sinsky CA, Poplau S, Brown R, Williams E; Healthy Work Place Investigators. Joy In Medical Practice: Clinician Satisfaction In The Healthy Work Place Trial. Health Aff (Millwood). 2017;36(10): 1808-1814.

28. Dolan ED, Mohr D, Lempa M, et al. Using a single item to measure burnout in primary care staff: a psychometric evaluation. J Gen Intern Med. 2015;30(5):582-587.

29. Bodenheimer T, Sinsky C. From triple to quadruple aim: care of the patient requires care of the provider. Ann Fam Med. 2014;12(6):573-576. 